\title{
Torsion, an Information State of Evolutionary Energy and Matter
}

\author{
Mircea Iosif NEAMTU \\ Department of Mathematics and Computer Sciences \\ Faculty of Computer Sciences, U.L.B.S. \\ Sibiu, ROMANIA \\ Email: neamtu12 [AT] yahoo.com
}

\author{
Mircea Valeriu ANGHEL \\ www.biodynamics.ro \\ Sibiu, ROMANIA \\ Email: mirceaanghel53 [AT] yahoo.com
}

\begin{abstract}
The torsion field as phenomenon and mechanism, has mainly drawn attention and its deep analysis came to the conclusion that torsion is a subtle phenomenon and the field is the element which contains and generates the state of torsion itself. Often torsional fields, space rotating fields, inter-dimensional ports and vortexes are mentioned in this context. We observed that the torsional field is created by dividing information [16], thus it is a component resulted from the informational dimension [19].
\end{abstract}

Keywords - informational dimension, imaginary sphere, spatial cube, word-of-state, cross entanglement, bios field, torsional field, center of balance, elemental particles, primal particles, elastic properties, inter-dimensional, vortexes, opposite properties, symmetrical state, primordial importance, hypothetical corners, scalar wave, scalar energy, boot energy, turning-torsion point, Mobius ring, etheric field, subtle level.

\section{INTRODUCTION}

\section{A. Torsion - a Short History}

In everyday life, torsion has been permanently interpreted as a physical state, resulted from a mechanical action. We define this force of state as a torsion force. This force creates phenomena, deformations and certain displacements that make up the object of study of a new chapter in Physics, Theoretical Mechanics and Matter Resistance.

Before physical phenomena have been profoundly analyzed, but mostly through the developments in Optics and Quantum Physics, torsion phenomena have appeared also in the subtle fields. This is why studying the torsion phenomena in the subtle fields and within the molecular and atomic field is necessary.

In the 1950s the Russian scientist Dr. N. A. Kozyrev (1908-1983) proved the existence of torsion energy, demonstrating that it flows in a sacred geometric spiral.

In parallel, as a support for the analysis of complex phenomena with which infinitesimal Physics was confronted, an appropriate mathematical support has been developed. This mathematics is capable to sustain the analysis effort of all phenomena from the Micro Particle Physics to Quantic
Physics. Hyperbolic Geometry, The Multidimensional Spaces Analysis, Scalar Algebra, Sphere's Geometry etc. have appeared, thus enabling Mathematics to sustain and demonstrate the existence of phenomena from the subtle state of matter.

Out of the dimensional evolution of matter, a surprising fact was born: a new and more profound level of origins' analysis of physical and biochemical phenomena derived. This analysis had, up to this moment, strange and incohesive interpretations.

\section{B. Introduction in the Information's Organization of the Chemical Elements' Table}

In its acceptance, any physical or existential state of matter is characterized by three dimensions: the electric, magnetic and informational dimension.[19] If the first two dimensions characterize position and orientation within the material field, the informational one characterizes the material state from several points of view.

From the informational bios field, we know that through the information's division mechanism (Fig. 1a) and the state of the field, the word of state repositions itself at any step and it reconfigures after an ascending or descending vortex structure, generating movement or direction, sense and balance of the torsion field (Fig 1b). [17], [18]

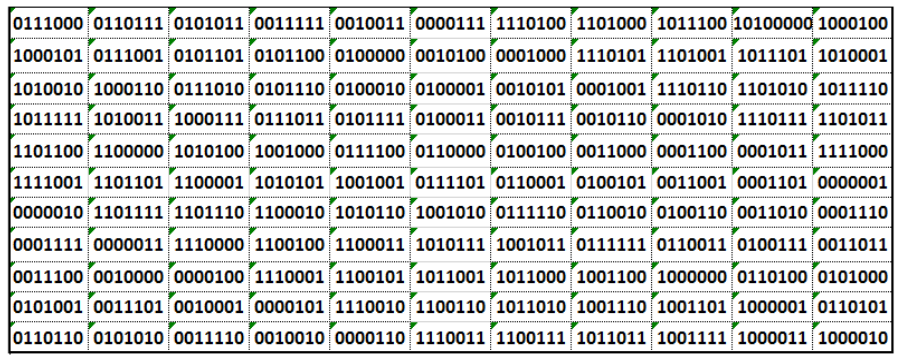
Fig. 1 a 


\begin{tabular}{|c|c|c|c|c|c|c|c|c|c|c|c|c|}
\hline 56 & 55 & 43 & 31 & 19 & 7 & 116 & 104 & 92 & 80 & 68 & & 671 \\
\hline 69 & 57 & 45 & 44 & 32 & 20 & 8 & 117 & 105 & 93 & 81 & & 671 \\
\hline 82 & 70 & 58 & 46 & 34 & 33 & 21 & 9 & 118 & 106 & 94 & & 671 \\
\hline 95 & 83 & 71 & 59 & 47 & 35 & 23 & 22 & 10 & 119 & 107 & & 671 \\
\hline 108 & 96 & 84 & 72 & 60 & 48 & 36 & 24 & 12 & 11 & 120 & & 671 \\
\hline 121 & 109 & 97 & 85 & 73 & 61 & 49 & 37 & 25 & 13 & 1 & & 671 \\
\hline 2 & 111 & 110 & 98 & 86 & 74 & 62 & 50 & 38 & 26 & 14 & & 671 \\
\hline 15 & 3 & 112 & 100 & 99 & 87 & 75 & 63 & 51 & 39 & 27 & & 671 \\
\hline 28 & 16 & 4 & 113 & 101 & 89 & 88 & 76 & 64 & 52 & 40 & & 671 \\
\hline 41 & 29 & 17 & 5 & 114 & 102 & 90 & 78 & 77 & 65 & 53 & & 671 \\
\hline \multirow[t]{2}{*}{54} & 42 & 30 & 18 & 6 & 115 & 103 & 91 & 79 & 67 & 66 & & 671 \\
\hline & & & & & & & & & & & 671 & \\
\hline 671 & 671 & 671 & 671 & 671 & 671 & 671 & 671 & 671 & 671 & 671 & & 7381 \\
\hline
\end{tabular}

Fig. 1 b

The analyze of this word of state offers a complete image of the matter's nature, meaning: its structure, its position within the informational structure and the nature of chemical elements from which it is made.

If, for analyzing the living matter cell of the bios field, a word of state of the informational dimension of six bits length is necessary [16],[17], in order to analyze the mineralogical field's structure or the chemical elements that comprise in it, we need an informational dimension word of state described by a word of seven bits length.[19]

In this context, the maximum number of chemical elements that comprises the informational dimension of the mineralogical field is $2^{7}=128$. Table of Chemical Elements contains only 120 elements, not all defined, but an appropriate analysis of these elements can be described on a square matrix of $11 \times 11=121$ elements.

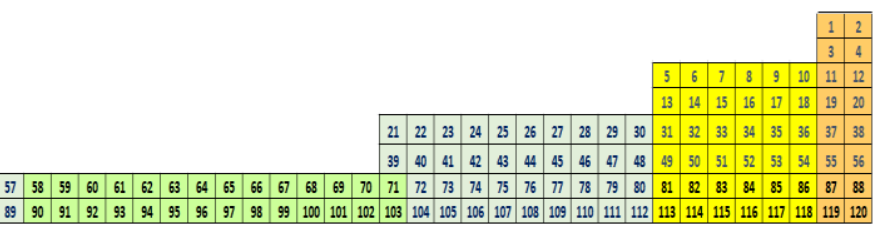

Fig. 2

By composing The Elements' Table two by two in four steps it results Fig. $3 a+$ Fig $3 b$ and to the end, it comes out Fig. 3c:

\begin{tabular}{|c|c|c|c|c|c|c|c|c|c|c|c|c|c|c|}
\hline \multirow{3}{*}{ I } & \multirow{2}{*}{\multicolumn{2}{|c|}{\begin{tabular}{l|l}
3 & 4 \\
& 1
\end{tabular}}} & & & & & & & & & & & & \\
\hline & & & & & & & & & & & & & & \\
\hline & 5 & 5 & & & & & & & & & & & & \\
\hline \multirow{3}{*}{ II } & 19 & & 13 & 14 & 15 & 16 & 17 & 18 & & & & & & \\
\hline & 12 & 11 & 10 & 9 & 8 & 7 & 6 & 5 & & & & & & \\
\hline & 31 & 31 & 23 & 23 & 23 & 23 & 23 & 23 & & & & & & \\
\hline \multirow{6}{*}{ III } & 56 & 55 & 5 & 53 & 52 & 51 & 50 & 49 & & & & & & \\
\hline & 37 & 38 & 3 & 32 & 33 & 34 & 35 & 36 & & & & & & \\
\hline & 93 & 93 & 8 & 85 & 85 & 85 & 85 & 85 & & & & & & \\
\hline & 48 & 47 & 46 & 45 & 44 & 43 & 42 & 41 & 40 & 39 & & & & \\
\hline & 21 & 22 & 23 & 24 & 25 & 26 & 27 & 28 & 29 & 30 & & & & \\
\hline & 69 & 69 & 69 & 69 & 69 & 69 & 69 & 69 & 69 & 69 & & & & \\
\hline \multirow{9}{*}{ IV } & 119 & 120 & 11 & \begin{tabular}{l|l}
8 & 117 \\
\end{tabular} & 116 & 115 & 114 & 113 & & & & & & \\
\hline & 88 & 87 & 8 & 82 & 83 & 84 & 85 & 86 & & & & & & \\
\hline & 207 & 207 & 19 & 199 & 199 & 199 & 199 & 199 & & & & & & \\
\hline & 112 & 111 & 110 & 109 & 108 & 107 & 106 & 105 & 104 & 103 & & & & \\
\hline & 71 & 72 & 73 & 74 & 75 & 76 & 77 & 78 & 79 & 80 & & & & \\
\hline & 183 & 183 & 183 & 183 & 183 & 183 & 183 & 183 & 183 & 183 & & & & \\
\hline & 102 & 101 & 100 & 99 & 98 & 97 & 96 & 95 & 94 & 93 & 92 & 91 & 90 & 89 \\
\hline & 57 & 58 & 59 & 60 & 61 & 62 & 63 & 64 & 65 & 66 & 67 & 68 & 69 & 70 \\
\hline & 159 & 159 & 159 & 159 & 159 & 159 & 159 & 159 & 159 & 159 & 159 & 159 & 159 & 159 \\
\hline
\end{tabular}

Fig. 3 a

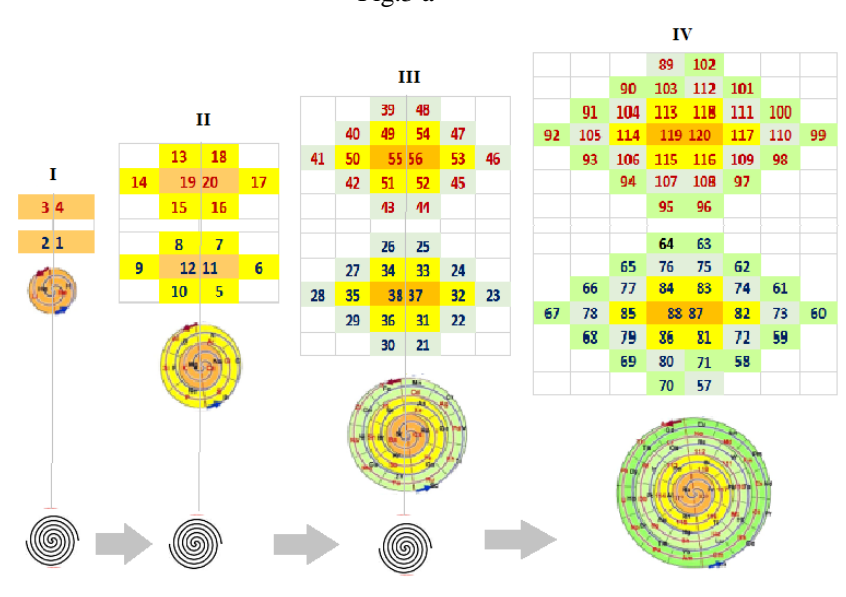

Fig. 3 b 


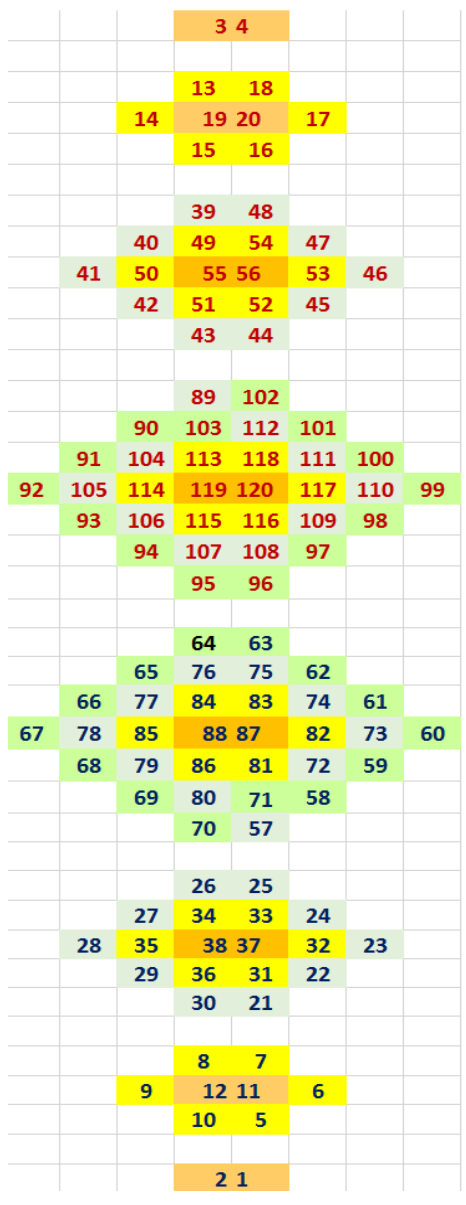

Fig. $3 \mathrm{c}$

Being a magic square $(11 \times 11)$ it must fulfill the formula: $\mathrm{n} \times\left(\mathrm{n}^{2}+1\right) / 2$, that is: $11 \times\left(11^{2}+1\right) / 2=1+2+\ldots+121=7381$.

Taking into account that the table of elements, at the beginning we knew only 120 elements, the calculations we will undertake will be written for: $1+2+\ldots+120=7260$.

\section{DEMONSTRATION}

\section{A. The Informational Basic of Matter Structure}

We will demonstrate the above state by generating the 120 elements starting from only two elements, which we call elemental particles (Fig.3c, Fig.4).

Using the torsion mechanism, given by the information division [19], we observe that the chemical elements are born by difference, positioning themselves on the opposite side in rhythmically balanced positions. The positions occupied are arranged in successive double spirals, like Fermat's double spiral or Tesla's two-starts coil. The elements of the chemical structure occupy successive positions of equilibrium with the center of the spirals and with the complementary elements, (Fig.3b,c), (Fig. 4).

Ex: $a+b=121$, namely: $23+98=121,14+107=121$, etc.
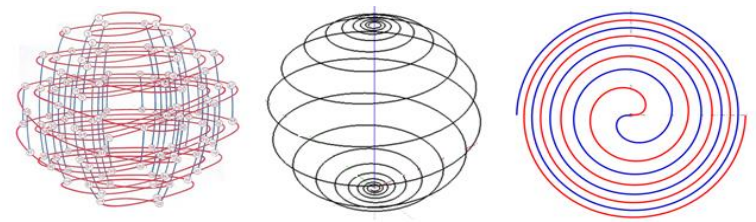

Fig. 4

Here we need to introduce two structural notions: the imaginary sphere and the special cube so that:

- This generation and distribution of the elements will take place in an imaginary sphere, with the specification that the structure of the model after which the elements are being generated, has to be balanced and equidistant from the surrounding ones.

A spatial cube can be defined as a model with symmetrical properties, being capable of division by two, while achieving a perfect symmetrical state.

If we return to an association by summing two tetrahedrons, we can imagine geometrical spatial forms that are being created by associating two-by-two four tetrahedrons, two-by-two eight tetrahedrons and so forth. In this context, by the association of 20 tetrahedrons, two-by-two an icosahedron is created. This figure is similar to a sphere. Two icosahedrons can form together a cube. Thus, a cube can be divided by 40 tetrahedrons. If these figures have opposite properties, any tetrahedron can only combine with an opposing tetrahedron, forming 20 new figures, meaning two such icosahedrons form two similar forms such as spheres. We will call these spheres primary particles with opposing properties that determine them to be active. The composing forces maintain these properties through a cubic model Fig.5.
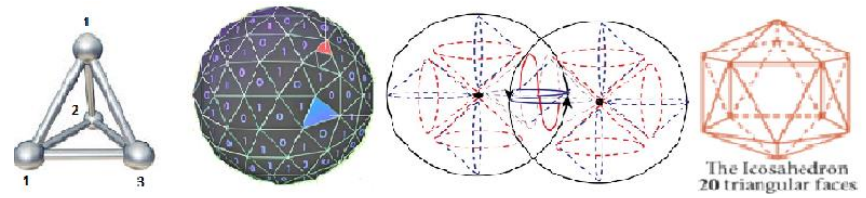

Fig. 5

In this context, the two spheres contain a total of 40 tetrahedrons. Keeping in mind that these have opposite properties, every tetrahedron will connect with another opposite tetrahedron, now forming 20 new figures, all while keeping the model in balance.

In order to form a cube, these new created figures, formed by the connection of two by two tetrahedrons, need to maintain the construction of the same model, only made out of smaller(unitary) cubes. As a fundamental condition, for two tetrahedrons being able to form a cube, they need to have elastic properties (Fig. 5), (Fig. 6).

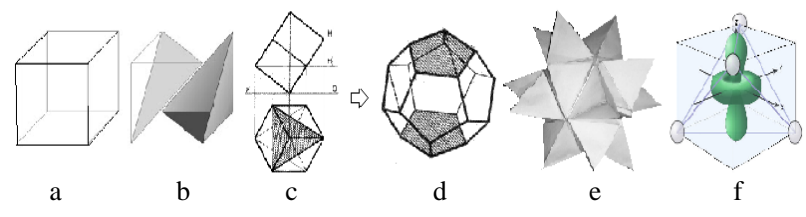

Fig.6 
Because every tetrahedron has four corners, two connected tetrahedrons will have just as many corners as the cube, so eight corners. It is important to keep in mind that, when it comes to geometrical figures that make out spatial structures, the corners are not being divided because they are of primordial importance (Fig.6b,c). The corners can change their composing angles, being able to create any structural figure, but are incapable of division and their number is always constant. These geometrical figures do not actually exist in reality, but they exist through their hypothetical corners that cumulates (or concentrates) information. These are the points that contain information and that create a force juncture with the diametrical opposite points. This spatial structure is formed as a three dimensional grid (entanglement) and is associated with the source and essence of everything that ever was, is or will be created (Fig. 6e,f).

If we analyze the big cubes through the construction of smaller cubes (unitary cubes that have sides equal to one unit) we discover the following: the biggest cube comprising the minimum number of smaller (unitary) cubes, (besides the unit $1 \times 1 \times 1=1$ unit cube), is the one built out of $2 \times 2 \times 2=8$ smaller (unitary) cubes. The following cube can be built out of $3 \times 3 \times 3=27$ smaller (unitary) cubes etc. (Fig. 7)

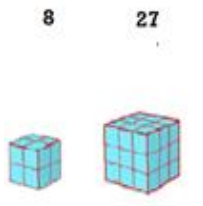

b

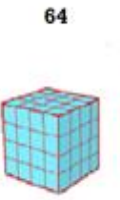

c

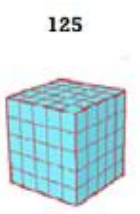

d

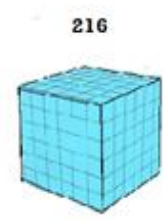

e

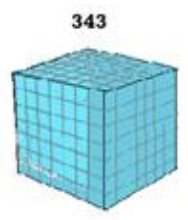

Fig.7 properties and functions. The basic structure of the six cubes form is a three dimensional grid (cross entanglement). This grid (cross entanglement) has a specific property: it never decomposes in smaller pieces. But it is able to yield and to take back the constructive elements (cubes) from its nearby proximity, balancing his contrasting dual properties needed to form matter (Fig. 8b,c,d) [19]. The central cube contains the subtle torsion mechanism and control of everything that will be created [17],[18],[19].

\section{B. The Creation of Chemical Elements' Table. The Symmetrical Property}

Thus, if we want to demonstrate the creation of the 120 elements from the Table of Chemical Elements, we need a spatial cube built from $5 \times 5 \times 5=125$ elements.

First of all, we will explain the symmetric property - the characteristic of symmetrical property within the division mechanism of particles.

In this concept, there are three types of symmetries generated by the division mechanism of a particle:

- Type 0: starting from the initial state, after a rotation of $360^{\circ}$, the information starts acting like a dot, meaning, that it looks just the same, no matter from which angle it is viewed (e.g.:"1001001","0101010","1101011”, ...).

- Type 1: starting from the initial state, after a rotation of $360^{\circ}$, the information returns to its initial state.

- Type 2: starting from the initial state, after a rotation of $180^{\circ}$, the information returns to its initial state.

To demonstrate this concept, we propose the following mathematical model corroborated with the I Ching Book.[20]

As for the elements corresponding to the I Ching Book, we attribute a binary prototype algorithm with binary values according to the studies, thus generating: $(|\rightarrow 1,| \rightarrow 0)$; where, for example: $\left(\left|\begin{array}{l}\mid \\ i\end{array}\right| \begin{array}{l}\mid \\ \mid\end{array} \mid \begin{array}{l}\mid \\ i\end{array} \rightarrow\right.$ 1010110).[16],[17],[19]

Here we need a word of state created from 7 bits, capable to explain a division of max. $2^{7}=128$ elements.

For example, starting from an initial given state: "1111110" we can write the information transmission model using a rotation mechanism with the "mirror-image" property, as follows: 20 cubes is 7 unitary cubes (Fig. 7). This must be the key to building a "spatial cube".

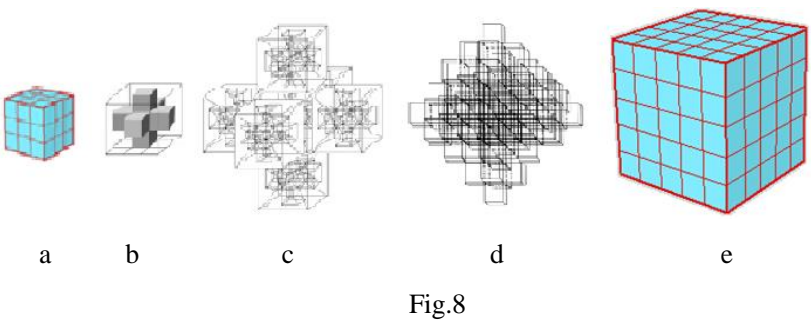

Here we need to specify that the missing 6+1 smaller cubes, form the basic structure of space and have different
Let us remember that for generating the 120 elements from the Table of Chemical Elements, we need a spatial cube built from $5 \times 5 \times 5=125$ elements or $5 \times 25=125$, five slices of 25 elements each. 
For building the cube's sequences and the calculation's order of this informational cube model, we need to know only 25 pairs of elements in order to generate the other ones (4x25). And from this 25 pairs we need to know only $9+7=16$ pairs of elements, from which: 9 pairs of elements are repeated (Fig.11c) and (6+1) are basic elements (the last seven from Fig.11c or Fig.13). The central element contains the requirement of the generating mechanism and the control of the model.[19] We propose that the basic information from where we start generating the cube should be: "1111111/0000000".

When the cube is generated, each sequence is represented by eight growth buds, and to build an eight buds sequences is enough to know anyone, but just one of them.

\section{Example (1):}

In this algorithm we want to generate $32=25+7$ sequences, each of 6 pairs of numbers. The splitting sequences order and their representation in the binary system is given by the following sphere of distribution (Fig. 9b,c):

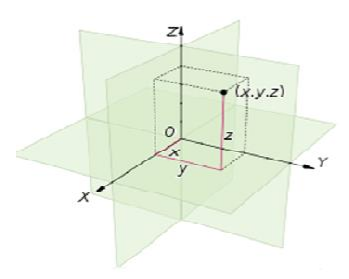

a

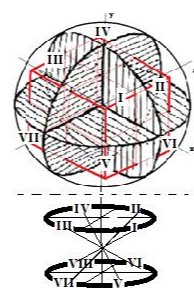

b

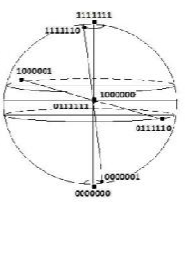

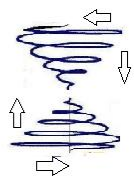

Fig.9

Where, I, II, III, IV, V, VI, VII, VIII represent the informational fields of the 8 quadrants of the sphere (Fig.9b), as follows:

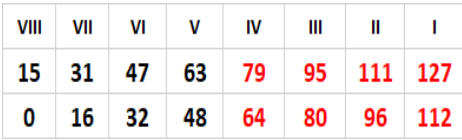

Fig.10a

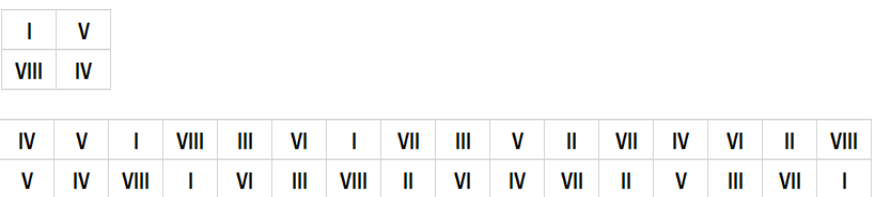

Fig.10b

The sequences' division and the calculation's order using a division mechanism algorithm and its representations is done both in the decimal and also in the binary system (fig. 11a) as follows:

$\begin{array}{llllll}127 & 126 & 63 & 64 & 1 & 0\end{array}$

$\begin{array}{llllll}125 & 124 & 31 & 96 & 3 & 2\end{array}$

$\begin{array}{llllll}123 & 122 & 47 & 80 & 5 & 4\end{array}$

$\begin{array}{llllll}121 & 120 & 15 & 112 & 7 & 6\end{array}$

$\begin{array}{llllll}119 & 118 & 55 & 72 & 9 & 8\end{array}$

$\begin{array}{llllll}117 & 116 & 23 & 104 & 11 & 10\end{array}$

$\begin{array}{llllll}115 & 114 & 39 & 88 & 13 & 12\end{array}$

$\begin{array}{llllll}113 & 112 & 7 & 120 & 15 & 14\end{array}$

$\begin{array}{llllll}111 & 110 & 59 & 68 & 17 & 16\end{array}$

$\begin{array}{llllll}109 & 108 & 27 & 100 & 19 & 18\end{array}$

$\begin{array}{llllll}107 & 106 & 43 & 84 & 21 & 20\end{array}$

$\begin{array}{llllll}105 & 104 & 11 & 116 & 23 & 22\end{array}$

$\begin{array}{llllll}103 & 102 & 51 & 76 & 25 & 24\end{array}$

$\begin{array}{llllll}101 & 100 & 19 & 108 & 27 & 26\end{array}$

$\begin{array}{llllll}99 & 98 & 35 & 92 & 29 & 28\end{array}$

$\begin{array}{llllll}97 & 96 & 3 & 124 & 31 & 30\end{array}$

$\begin{array}{llllll}95 & 94 & 61 & 66 & 33 & 32\end{array}$

$\begin{array}{llllll}93 & 92 & 29 & 98 & 35 & 34\end{array}$

$\begin{array}{llllll}91 & 90 & 45 & 82 & 37 & 36\end{array}$

$\begin{array}{llllll}89 & 88 & 13 & 114 & 39 & 38\end{array}$

$\begin{array}{llllll}87 & 86 & 53 & 74 & 41 & 40\end{array}$

$\begin{array}{llllll}85 & 84 & 21 & 106 & 43 & 42\end{array}$

$\begin{array}{llllll}83 & 82 & 37 & 90 & 45 & 44\end{array}$

$\begin{array}{llllll}81 & 80 & 5 & 122 & 47 & 46\end{array}$

$\begin{array}{llllll}79 & 78 & 57 & 70 & 49 & 48\end{array}$

$\begin{array}{llllll}77 & 76 & 25 & 102 & 51 & 50\end{array}$

$\begin{array}{llllll}75 & 74 & 41 & 86 & 53 & 52\end{array}$

$\begin{array}{llllll}73 & 72 & 9 & 118 & 55 & 54\end{array}$

$\begin{array}{llllll}71 & 70 & 49 & 78 & 57 & 56\end{array}$

$\begin{array}{llllll}69 & 68 & 17 & 110 & 59 & 58\end{array}$

$\begin{array}{llllll}67 & 66 & 33 & 94 & 61 & 60\end{array}$

$\begin{array}{llllll}65 & 64 & 1 & 126 & 63 & 62\end{array}$
111111111111100111111100000000000010000000 111110111111000011111110000000000110000010 111101111110100101111101000000001010000100 111100111110000001111111000000001110000110 111011111101100110111100100000010010001000 111010111101000010111110100000010110001010 111001111100100100111101100000011010001100 111000111100000000111111100000011110001110 110111111011100111011100010000100010010000 110110111011000011011110010000100110010010 110101111010100101011101010000101010010100 110100111010000001011111010000101110010110 110011111001100110011100110000110010011000 110010111001000010011110110000110110011010 110001111000100100011101110000111010011100 1100001110000000000111111110000111110011110 101111110111100111101100001001000010100000 101110110111000011101110001001000110100010 01101110110100101101101001001001010100100 101100110110000001101111001001001110100110 101011110101100110101100101001010010101000 101010110101000010101110101001010110101010 101001110100100100101101101001011010101100 101000110100000000101111101001011110101110 100111110011100111001100011001100010110000 100110110011000011001110011001100110110010 100101110010100101001101011001101010110100 100100110010000001001111011001101110110110 1000111100011001100011001110011110010111000 100010110001000010001110111001110110111010 100001110000100100001101111001111010111100 100000110000000000001111111001111110111110

Fig.11a
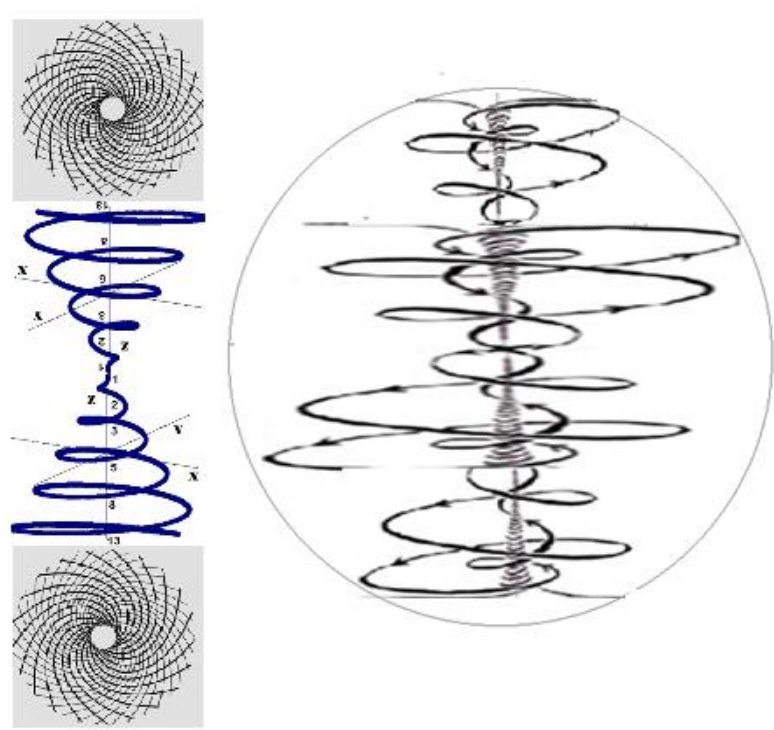

Fig.11b 


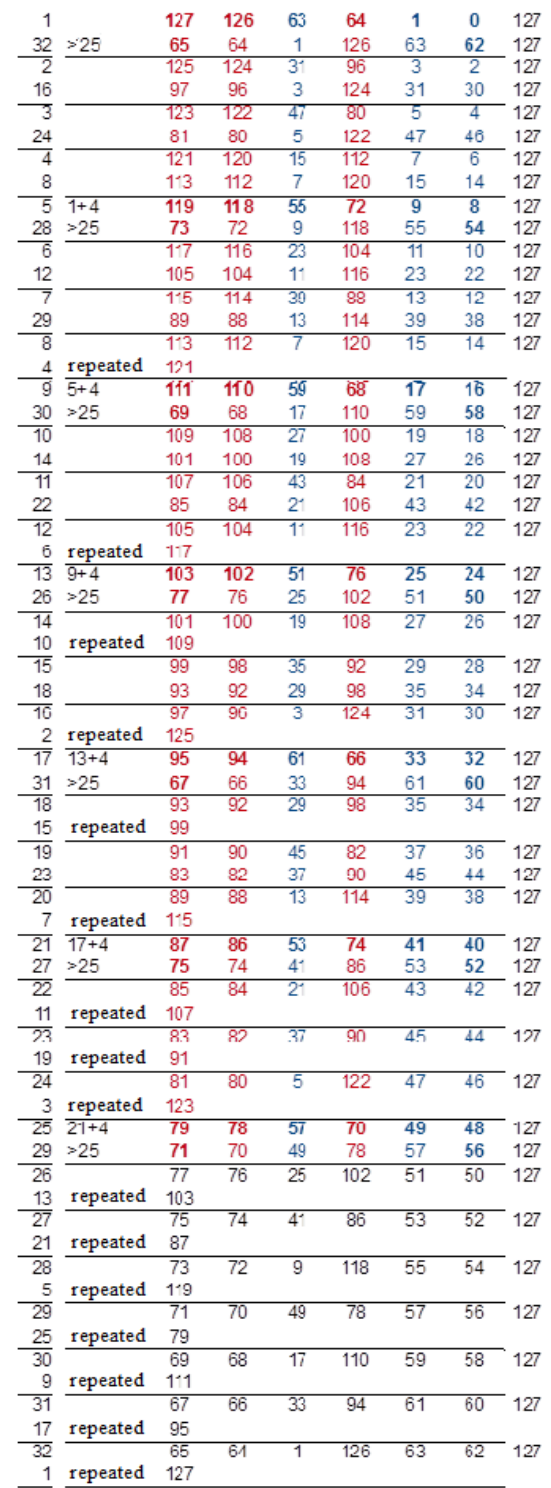

Fig.11c

\section{The Informational Affinity Bonds Between Elements}

In order to observe the informational affinity bonds between the elements, we associate two by two sequences. In this way, the division sequences obtained through the rotation mechanism uses the property of "mirror sight" to the corresponding binary information (Fig. 12).

\begin{tabular}{|c|c|c|c|c|c|c|c|}
\hline & & 127 & 126 & 63 & 64 & 1 & 0 \\
\hline & & 65 & 64 & 1 & 126 & 63 & 62 \\
\hline & 2 & 125 & 124 & 31 & 96 & 3 & 2 \\
\hline & 16 & 97 & 96 & 3 & 124 & 31 & 30 \\
\hline & 3 & 123 & 122 & 47 & 80 & 5 & \\
\hline & 24 & 81 & 80 & 5 & 122 & 47 & 46 \\
\hline & 4 & 121 & 120 & 15 & 112 & 7 & \\
\hline & 8 & 113 & 112 & 7 & 120 & 15 & 14 \\
\hline & 5 & 119 & 118 & 55 & 72 & 9 & \\
\hline & 28 & 73 & 72 & 9 & 118 & 55 & 54 \\
\hline & 6 & 117 & 116 & 23 & 104 & 11 & 10 \\
\hline & 12 & 105 & 104 & 11 & 116 & 23 & 22 \\
\hline & 7 & 115 & 114 & 39 & 88 & 13 & 12 \\
\hline & 20 & 89 & 88 & 13 & 114 & 39 & 38 \\
\hline \multirow[b]{2}{*}{ B } & 8 & 113 & 112 & 7 & 120 & 15 & 14 \\
\hline & 4 & 121 & 120 & 15 & 112 & 7 & 6 \\
\hline \multirow[b]{2}{*}{9} & 9 & 111 & 110 & 59 & 68 & 17 & 16 \\
\hline & 30 & 69 & 68 & 17 & 110 & 59 & 58 \\
\hline \multirow[b]{2}{*}{10} & 10 & 109 & 108 & 27 & 100 & 19 & 18 \\
\hline & 14 & 101 & 100 & 19 & 108 & 27 & 26 \\
\hline \multirow[b]{2}{*}{1} & 11 & 107 & 106 & 43 & 84 & 21 & 20 \\
\hline & 22 & 85 & 84 & 21 & 106 & 43 & 42 \\
\hline & 12 & 105 & 104 & 11 & 116 & 23 & 22 \\
\hline & 6 & 117 & 116 & 23 & 104 & 11 & 10 \\
\hline \multirow[b]{2}{*}{3} & 13 & 103 & 102 & 51 & 76 & 25 & 24 \\
\hline & 26 & 77 & 76 & 25 & 102 & 51 & 50 \\
\hline \multirow[b]{2}{*}{4} & 14 & 101 & 100 & 19 & 108 & 27 & 26 \\
\hline & 10 & 109 & 108 & 27 & 100 & 19 & 18 \\
\hline & 15 & 99 & 98 & 35 & 92 & 29 & 28 \\
\hline 15 & 18 & 93 & 92 & 29 & 98 & 35 & 34 \\
\hline & 16 & 97 & 96 & 3 & 124 & 31 & 30 \\
\hline & 2 & 125 & 124 & 31 & 96 & 3 & 2 \\
\hline & 17 & 95 & 94 & 61 & 66 & 33 & 32 \\
\hline & 31 & 67 & 66 & 33 & 94 & 61 & 60 \\
\hline & 18 & 93 & 92 & 29 & 98 & 35 & 34 \\
\hline & 15 & 99 & 98 & 35 & 92 & 29 & 28 \\
\hline & 19 & 91 & 90 & 45 & 82 & 37 & 36 \\
\hline & 23 & 83 & 82 & 37 & 90 & 45 & 44 \\
\hline & 20 & 89 & 88 & 13 & 114 & 39 & 38 \\
\hline & 7 & 115 & 114 & 39 & 88 & 13 & 12 \\
\hline & 21 & 87 & 86 & 53 & 74 & 41 & 40 \\
\hline & 27 & 75 & 74 & 41 & 86 & 53 & 52 \\
\hline & 22 & 85 & 84 & 21 & 106 & 43 & 42 \\
\hline & 11 & 107 & 106 & 43 & 84 & 21 & 20 \\
\hline & 23 & 83 & 82 & 37 & 90 & 45 & 44 \\
\hline & 19 & & 90 & 45 & 82 & 37 & 36 \\
\hline & 24 & 81 & 80 & 5 & 122 & 47 & 46 \\
\hline & 3 & 123 & 122 & 47 & 80 & 5 & 4 \\
\hline & 25 & 79 & 78 & 57 & 70 & 49 & 48 \\
\hline & 29 & & 70 & 49 & 78 & 57 & 56 \\
\hline & 26 & 77 & 76 & 25 & 102 & 51 & 50 \\
\hline & 13 & 103 & 102 & 51 & 76 & 25 & 24 \\
\hline & 27 & 75 & 74 & 41 & 86 & 53 & 52 \\
\hline & 21 & 7 & 86 & 53 & 74 & 41 & 40 \\
\hline & 28 & 73 & 72 & 9 & 118 & 55 & 54 \\
\hline & 5 & 119 & 118 & 55 & 72 & 9 & \\
\hline & 29 & 71 & 70 & 49 & 78 & 57 & 56 \\
\hline & 25 & 79 & 78 & 57 & 70 & 49 & 4 \\
\hline & 30 & & 68 & 17 & 110 & 59 & 58 \\
\hline & 9 & 111 & 110 & 59 & 68 & 17 & 16 \\
\hline & 31 & 67 & 66 & 33 & 94 & 61 & 60 \\
\hline & 17 & 95 & 94 & 61 & 66 & 33 & 32 \\
\hline & 32 & 65 & 64 & 1 & 126 & 63 & 62 \\
\hline & 1 & 127 & 126 & 63 & 64 & 1 & 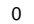 \\
\hline
\end{tabular}

111111111111100111111100000000000010000000 100000110000000000001111111001111110111110 111110111111000011111110000000000110000010 $\frac{1100001110000000000111111100001111100111110}{1111011111101001011111010000}$ 10100011010000000101111010010111010110 11110011111000 0001111 111000000001110000110 11100011100000000111111000000111000110 $\frac{1110001111000000000111111100000011110001110}{1110111111011001101111001000}$

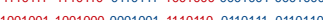
100100110010000001001111011001101110110110 1101001 1ho $1101001110100000010+1111010000101110010110$

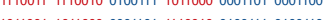
$\frac{101100110110000001101111001001001110100110}{1100011110000000011111100000011110001110}$ H. 1111001111100000011111110000000011100000110

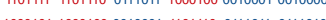
100010110001000010001110111001110110111010

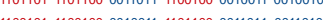
110010111001000010011110110000110110011010 10.010 ror $101010110101000010101+10101001010110101010$ 11010011101000000101111101000101110010110 111010111101000010111110100000010110001010 110011111001100110017100110000110010011000 100110110011000011001110011001100110110010 $1100101+1001000010011710110000110110011010$ 110110111011000011011110010000100110010010 110001111000100100011101110000111010011100 101110110111000011101110001001000110100010 110000111000000000011111110000111110011110 11111011111100001111111000000000001100000010 101111110111100111101100001001000010100000 100001110000100100001101111001111010111100 101110110111000011101110001001000110100010 110001111000100100011101110000111010011100 101101110110100101101101001001001010100100 101001110100100100101101101001011010101100 101100110110000001101111001001001110100110 111001111100100100111101100000011010001100 101011110101100110101100101001010010101000 100101110010100101001101011001101010110100 101010110101000010101110101001010110101010 110101111010100101011101010000101010010100 101001110100100100101101101001011010101100 101101110110100101101101001001001010100100 101000110100000000101111101001011110101110 111101111110100101111101000000001010000100 100111110011100111001100011001100010110000 100011110001100110001100111001110010111000 100110110011000011001110011001100110110010 110011111001100110011100110000110010011000 100101110010100101001101011001101010110100 101011110101100110101100101001010010101000 100100110010000001001111011001101110110110 111011111101100110111100100000010010001000 100011110001100110001100111001110010111000 100111110011100111001100011001100010110000 100010110001000010001110111001110110111010 110111111011100111011100010000100010010000 100001110000100100001101111001111010111100 101111110111100111101100001001000010100000 100000110000000000001111111001111110111110 111111111111100111111100000000000010000000

Fig. 12

From the following pairs, six are basic (are not repeated) (Fig.13), and one, the first pair 127/0, represents the beginning and the end of the binary information (1111111) or (0000000). The pair 127/0 represents the primordial information from where the division starts (one of 7 basic elements' pairs):

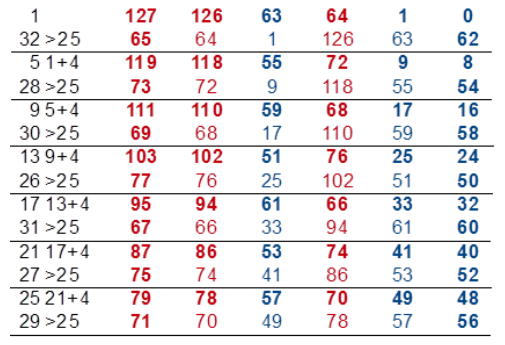

Fig.13 
E.g.: We just have seen that each sequence is represented by eight growing buds and for creating out an eight buds sequence, it is sufficient to know anyone of them. If we know one of the numbers that form the six pairs, it can be discovered any other number of the any of the rest five pairs.

The numbers represented (colored) in blue always contain values from 0:63 and the other ones colored in red the values from 64:127. (Fig.11a, Fig. 11c, Fig.12)

\section{Example (2):}

P1. Let's analyze a random number, such as: 103

P2. We set 103 to the left side. Deducting 127-103, thus setting 24 to the right, we have calculated the opposite number.

P3. The next elements will be calculated by compensation: if a unit is deducted from the left side element, one needs to be added to the symmetrical element from the right; thus: $103-1=102,24+1=25$. We have the elements 102 to the right and 25 to the left.

P4. We decompose the element 25 in two elements of closest values, 12 and $13(12+13=25)$.

P5. In order to discover the upper elements the following calculations need to occur:

- The ones marked in blue $(<64)$ we deduce from $64-$ the highest value from the two values $(12 ; 13)$ that make out the number 25 , meaning: $64-13=51$. We need to specify that the highest number from the two elements of closest values is also the next step in order to generate the algorithm. Now, $51=26+25$. For a complete creation we need 25 elements and the highest from the two elements that compose 51 is 26 . The element $26>25$ than the number we need 103-26=77. Meaning that its pair $(103: 77)$ is part of the basic structure.

- The ones marked in red, $(=>64)$ we add to 64 the lowest value from the two $(12 ; 13)$. These values make out the number 25 , meaning: $64+12=76$. We have the elements 51 to the right and 76 to the left.

P6. To the lower level elements the two values begin/end are found by compensation. Therefore if we add one to 76 we have 77 to the right and we deduct one from 51 we have 50 to the left. For the next step the lower level middle elements are deducted from the upper level elements: switching the position of the string.

This can be easily written as follows: (Fig.14).

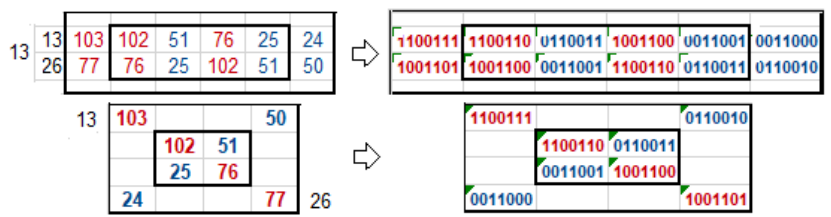

Fig. 14
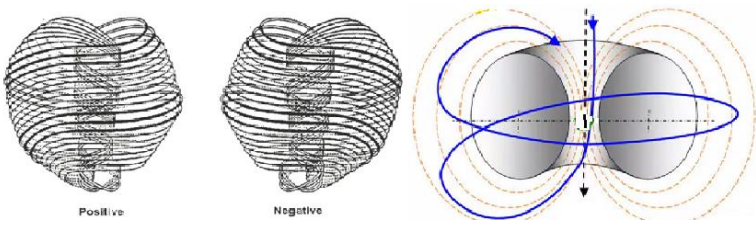

Fig.15

\section{E. The Balance and the Order of the Chemical Elements'} Table as a Result of Informational Torsion Structure

The balance and the order of the Chemical Elements' Table in the $3 \mathrm{D}$ space can be described by the follow matrix structure:

\begin{tabular}{|c|c|c|c|c|c|c|c|c|c|c|}
\hline 11 & 10 & 9 & 8 & 7 & 6 & 5 & 4 & 3 & 2 & 1 \\
\hline 22 & 21 & 20 & 19 & 18 & 17 & 16 & 15 & 14 & 13 & 12 \\
\hline 33 & 32 & 31 & 30 & 29 & 28 & 27 & 26 & 25 & 24 & 23 \\
\hline 44 & 43 & 42 & 41 & 40 & 39 & 38 & 37 & 36 & 35 & 34 \\
\hline 55 & 54 & 53 & 52 & 51 & 50 & 49 & 48 & 47 & 46 & 45 \\
\hline 66 & 65 & 64 & 63 & 62 & 61 & 60 & 59 & 58 & 57 & 56 \\
\hline 77 & 76 & 75 & 74 & 73 & 72 & 71 & 70 & 69 & 68 & 67 \\
\hline 88 & 87 & 86 & 85 & 84 & 83 & 82 & 81 & 80 & 79 & 78 \\
\hline 99 & 98 & 97 & 96 & 95 & 94 & 93 & 92 & 91 & 90 & 89 \\
\hline 110 & 109 & 108 & 107 & 106 & 105 & 104 & 103 & 102 & 101 & 100 \\
\hline 121 & 120 & 119 & 118 & 117 & 116 & 115 & 114 & 113 & 112 & 111 \\
\hline
\end{tabular}

Fig.16

We can relative easily observe that the system establish a balance two by two on diagonal and that the composing elements generate the same balanced value. For the elements of the matrix that are situated on symmetrical positions, on the opposite diameter, we have a permanent system balance state of 122. Thus, the system is in balance by passing through the center $50+2 \times(5+5)=70$ times (Fig.16), or 7 times, creating a 7 times vortex (informational twist).[18],[19] Therefore, 121 elements, plus the 7 virtual ones from the central vortex, create $128=2^{7}$ elements witch form the Table of Chemical Elements. For the chemical system to be balanced from a point of view of the electrical, magnetic and informational dimension, it needs to keep the order in the repartition matrix of the system (Fig.18).

Even more, using a 7 bits string as a word of state, knowing the beginning and the end, to be more precise, we put the two words of state: 1111111 and 0000000 , into a sphere or a $5 \times 5 \times 5=125$ cube, using the above model as a matrix structure, we can generate any of the two geometric models of the matter structure, as follows (Fig.17 + Fig.18).[18],[19]

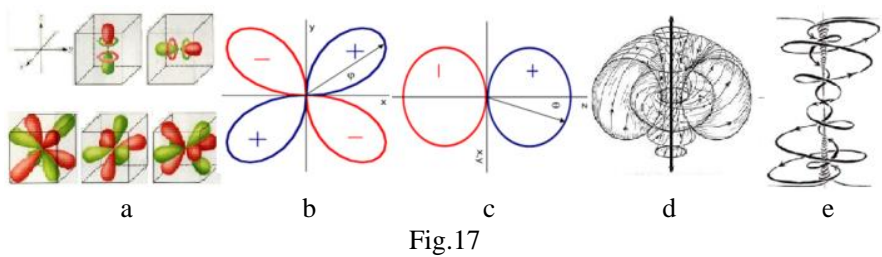

Analyzing the above system, we can see that all physicchemical elements of material reality have been defined by using a structure of matter defined into a spatial cube of $5 \times 5 \times 5=125$ chemical elements.

Only 32 elements are needed in order to describe the whole structure, meaning $25+7$. The 25 from the physical state 
and the $6+1=7$ from the virtual torsion state of the balanced center of the model described above. The torsion state is generated by the division of information, contained into the word of state [16],[17].

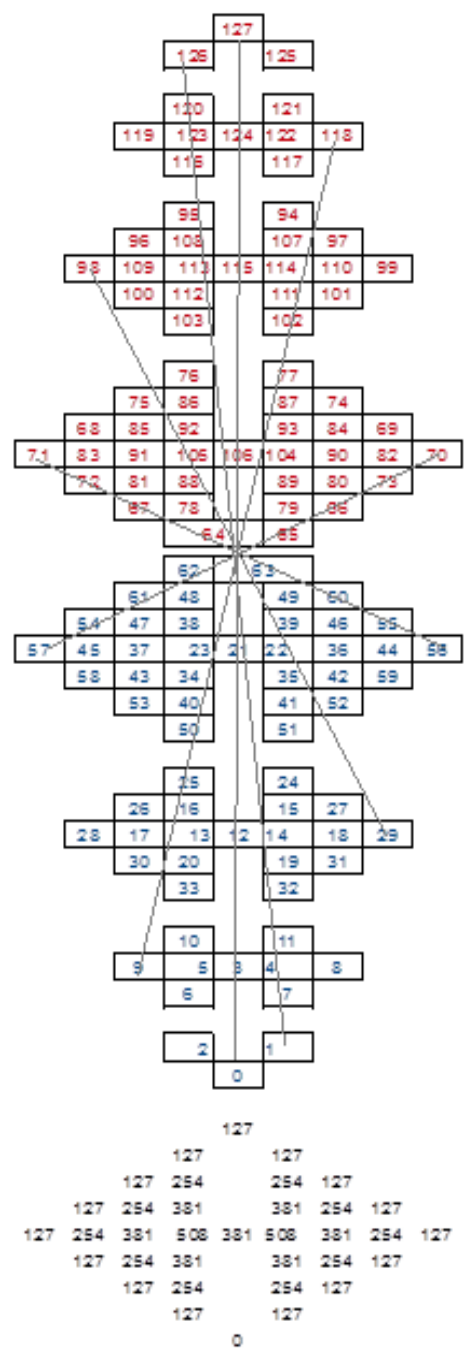

Fig. 18

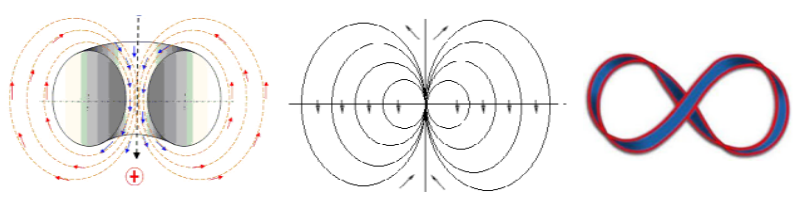

Fig. 19

Thus, the basic model of the Table of Chemical Elements structure is the result of a proces that keeps and sustaines a perfect balanced infomational model, both in an imaginary sphere and into a cube of space.

The balace informational calculus' result (Fig.18) can be shown as follows:

- We choose, by random, one specific informational value belonging to a concentric circle or square, defined by one of the elements $[127,254,381,508]$. The

evidence of the informational values of the forth concentric circles or squares, will be shown from exterior (outdoor) to interior (indoor) of the mathematical structure, like this:

$\circ 127$ informational value is the caracteristic of the first exterior (outdoor) circle or square: $127=74+53$;

o The next informational value caracteristic of the second circle or square, into interior (indoor) direction is: $127+127=127 \times 2=254 ; 254=96+85+42+31$;

o The third level of the circles' or squares' caracteristic informational value is: $254+127=127 \times 3=381$; $381=117+111+89+38+16+10$;

oThe forth level, the interior (indoor) level of the circles' or squares' caracteristic is: $381+127=127 \times 4=$ $508 ; 508=126+123+113+105+22+14+4+1$.

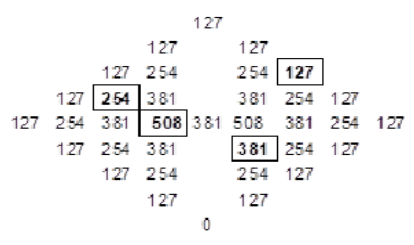

Fig.20

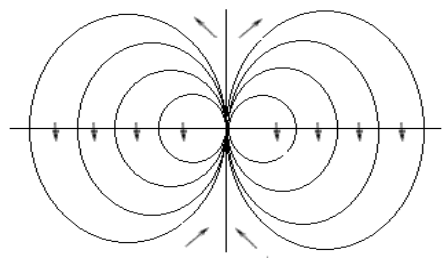

\section{F. Informational Dimension and Torsion as Longitudinal Wave Generator}

The simetry and the balace's informational result of the circles' or squares' caracteristic from the exterior (outdoor) to the interior (indoor) (Fig. 20) can be shown as follows:

The structure describing the Chemical Elements' Table consists in 128(from 0 to 127 ) elementary information.

But, 7 elemental cubes are of different structure, with other properties, other functions and do not participate in the formation of matter (Fig.8b). These 7 elemental cubes form a separate basic structure of space, which never breaks down into smaller fragments. This structure resembles a threedimensional mesh, which can yield elemental cubes necessary for the formation of matter, but also receive them back by balancing the opposite properties [18], [19].

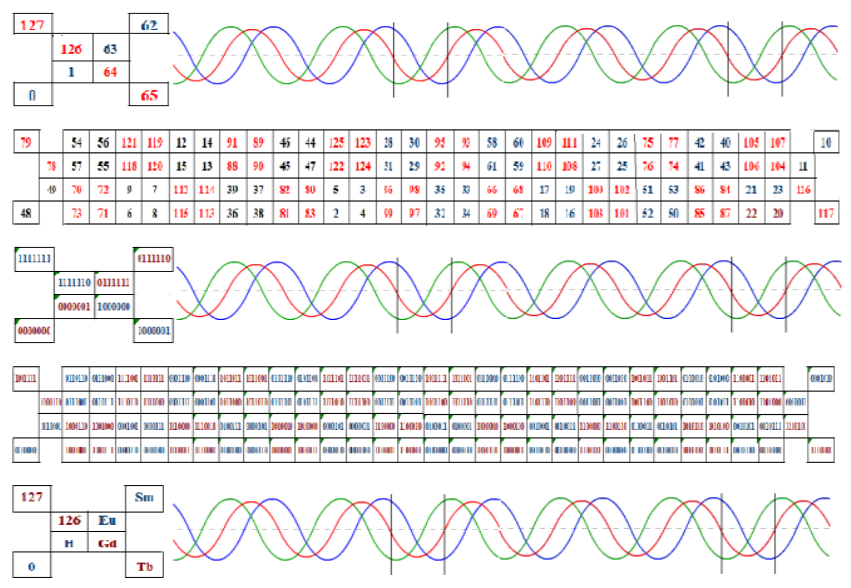




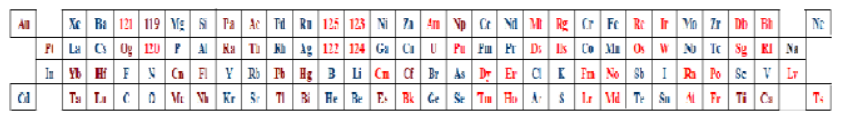

Fig .21

We can rearrange this information strings in four groups, ordered after the basic informational dimension build in.

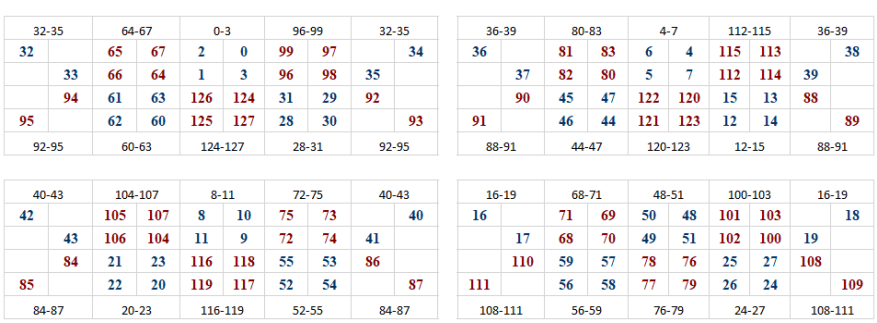

or:

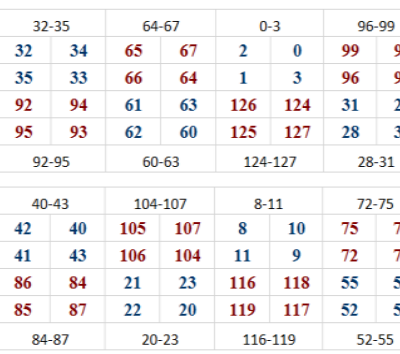

\begin{tabular}{|c|c|c|c|c|c|c|c|}
\hline \multicolumn{2}{|c|}{$36-39$} & \multicolumn{2}{|c|}{ 80-83 } & \multicolumn{2}{|c|}{$4-7$} & \multicolumn{2}{|c|}{$112-115$} \\
\hline 36 & 38 & 81 & 83 & 6 & 4 & 115 & 113 \\
\hline 39 & 37 & 82 & 80 & 5 & 7 & 112 & 114 \\
\hline 88 & 90 & 45 & 47 & 122 & 120 & 15 & 13 \\
\hline 91 & 89 & 46 & 44 & 121 & 123 & 12 & 14 \\
\hline \multicolumn{2}{|c|}{ 88-91 } & \multicolumn{2}{|c|}{$44-47$} & \multicolumn{2}{|c|}{$120-123$} & \multicolumn{2}{|c|}{$12-15$} \\
\hline \multicolumn{2}{|c|}{$16-19$} & \multicolumn{2}{|c|}{$68-71$} & \multicolumn{2}{|c|}{$48-51$} & \multicolumn{2}{|c|}{$100-103$} \\
\hline 16 & 18 & 71 & 69 & 50 & 48 & 101 & 103 \\
\hline 19 & 17 & 68 & 70 & 49 & 51 & 102 & 100 \\
\hline 108 & 110 & 59 & 57 & 78 & 76 & 25 & 27 \\
\hline 111 & 109 & 56 & 58 & 77 & 79 & 26 & 24 \\
\hline \multicolumn{2}{|c|}{$108-111$} & \multicolumn{2}{|c|}{$56-59$} & \multicolumn{2}{|c|}{$76-79$} & \\
\hline
\end{tabular}

Fig.22

Thus, we observe that through this mechanism, the structure of matter goes through a reconversion when it enters into the torsion point of the balance center (formed by $6+1=7$ elements), both from polarization and from the balance's repositioning point of view. From Tesla's point of view this mechanism of turning-torsion point, like a Mobius ring, generates an elementary longitudinal wave, called scalar wave, (Fig.20, Fig.21, Fig.22). And this wave generates a scalar field and an unit amount of scalar energy [33], [34], [35], [37].

\section{G. Matter Proprieties' Related to the Information Dimension and Torsion}

This Mobius torsion ring, repeated 7 times into the balance center of the model, shows that the matter keeps its balance on all spatial directions. And on the vicinities formed nearly to the propagation directions, the groups of elements establish lineage and attraction bonds. From here, the tendency of such chemical elements to form preferential components with other chemical elements belonging to their own groups or vicinity, is clearly obvious. It means it is the affinity property between the chemical elements that belong to the same specific group or vicinity of elements, with the same basic informational dimension.

The physical properties, such as position, impulse, spin and polarization of the particles are generated through the division of information and establish the correlation between particles, the scalar wave, the scalar energy and field, these creating the quantic bonds.
This synergic behavior is identical to the elements for the both ends of the physic-chemical structure of Chemical Elements' Table.

The last elements belonging to the Chemical Elements' Table, display a behavior of heavy metals and rare substances, tied to the coarse matter. The elements at the other end, at the beginning of the Chemical Elements' Table, such as Hydrogen, display a behavior of transitional border towards the subtle fields and towards the ether plane.

\section{CONCLUSION}

It is not a surprise that, in his first works about the Table of Chemical Elements, Mendeleev mentions Ether as a starting element. And it is also not a surprise that into the structure of cosmic Ether, the founding matter's element of the universe is Hydrogen. Hydrogen, into different structural forms ("light" or subtle) composes the clouds of galaxies and stars. If, into the material field, Hydrogen appears as a so-called "light" element (Hydrogen, Deuterium, Tritium), into the subtle field, it appears as a psychological element (H192, H96, H48, etc.) [27].

We can easily observe that the fields (the material field into an atomic level and the subtle field into an etheric level) share a logical and an informational bond, characterized by certain fluency and an informational transition. This informational bond is able to generate, to build, to govern, and to control, through the shown mechanisms, the entire universal energy and construction to any level.

Each elementary Mobius ring of information creates an elementary scalar wave and an elementary quantum of scalar energy. As we have seen, torsion as result of the division of information is the key of all processes to any structure, to any level in Universe [19]. It means, it results a huge quantity of scalar energy to the Universe level, with no limits. This quantity of energy represents the basis, the boot energy of all energetic processes of the reality, the source and the fuel of the matter, [2],[30],[33],[34],[35],[37],[38],[39],[40],[41],[43].

We just have shown that the reality is not only under the control of the forces and the commands from the physical or the touchable reality level. There is another level, the subtle level located into the informational dimension that precede, interfere and govern the whole universal construction; with all the implication generated of this approach type, towards a New Physics and with all existential questions regarding the Genesis of Life and what we generally name Evolution.

\section{REFERENCES}

[1] Vasile Conta, Teoria fatalismului. Teoria ondulaţiei universale, Bucureşti, Editura Ştiinţifică, 1969;

[2] Filosofia Obiectuala, http://filosofia.obiectuala.ro/ro/cartea/index.html;

[3] Frank J. Tipler, Anchor Books, "The Physics of Immortality. Modern Cosmology, God and the Resurection of the Dead“, Anchor Books, New York, September, 1995.

[4] Rupert Sheldrake - Mind, Memory and Archetype Morphic Resonance, Psychological Perspectives, 1997;

[5] Fritjof Capra, "The Tao of Physics. An exploration of the parallels 
between Modern Physics and Eastern mysticism“, Shambhala Publication, Inc. 1123 Spruce Street, Colorado, 80302, Boulder, 1975;

[6] Aristotel, Metafizica, Editura Academiei RSR, Bucureşti, 1965;

[7] Aristotel, Fizica, Editura Ştiinţifică, Bucureşti, 1966;

[8] Blaga, L., Trilogia cosmologică, Editura Humanitas, Bucureşti, 1997;

[9] Blaga, L., Experimentul şi spiritul matematic, Editura Ştiinţifică, Bucureşti, 1969;

[10] Hegel, G.W. Ştiinţa logicii, Editura Academiei RSR, Bucureşti, 1966;

[11] Heisenberg, W., Principiile fizice ale teoriei cuantice, Editura Ştiinţifică, Bucureşti, 1969;

[12] Prigogine, I., Stengers, I., Noua alianţă. Metamorfoza ştiinţei, Editura Politică, Bucureşti, 1984;

[13] Schrödinger, E., Ce este viaţa? Spirit şi materie, Editura Politică, Bucureşti, 1980;

[14] Restian, Adrian., Unitatea lumii şi integrarea ştiinţelor sau integronica, Editura Ştiinţifică şi Enciclopedică, Bucureşti, 1989;

[15] Neamtu I.M., Anghel V.M., "Mathematical Laws Used in Rapid Treating and Diagnosis Techniques and Methods by the Projection of the Human Body on Four Dimensions", IJCIT, ISSN: 2279 - 0764, Vol 3, Issue 3 , 2014;

[16] Neamtu I.M., Anghel V.M., The binary Pattern of Cell Grow and Division, Online International Interdisciplinary Research Journal, Vol. V-Issue I, Jan-Feb 2015/ISSN 2249-9598;

[17] Neamtu I.M., Anghel V.M.; Mathematical Model of Cell Division, IJCIT, ISSN: 2279 - 0764, Vol 5, Issue 1, 2016;

[18] Neamtu I.M., Anghel V.M., The dynamics of information between order and chaos, IJCIT, ISSN: 2279 - 0764, Vol. 06-Issue 05, September 2017

[19] Neamtu I.M., Anghel V.M, Information State and the General Model of Matter Structures, IJCIT, ISSN: 2279-0764, Vol. 08-Issue 05, September 2019;

[20] I Ching: The Book of Change, Thomas Cleary, Shambhala PublicationsInc, 10 March 1992;

[21] Friedrich Cramer, "Chaos und Ordnung. Die komplexe struktur des lebendigen" Deutsche Verlags - Anstalt GmbH Stuttgart 1988;

[22] Alexander Altland, Ben D. Simons, "Condensed Matter Field Theory", Cambridge University Press, Second Edition, 2010;

[23] Brian J. McCartin, "MYSTERIES OF THE EQUILATERAL TRIANGLE", Applied Mathematics Kettering University, First published, 2010;

[24] Clifford A. Pickover; The Zen of Magic Squares; Circles, and Stars; Published by Princeton University Press; Second printing; Princeton, New Jersey, 2003;

[25] Bengtsson I; Życzkowski K ., Geometria statelor cuantice. O introducere în entanglementul cuantic, Cambridge: Cambridge University Press, 2017 ;

[26] Leadbeater, Charles W. \& Besant, Annie, Occult Chemistry, http://www.subtleenergies.com/ormus/oc/occult.pdf;

[27] Aissel Selim, Cartea Occidentala a Vietii si a Mortii, Editura Prestige, Bucuresti, 2018;

[28] International Union of Pure and Applied Chemistry, Nomenclature of Inorganic Chemistry, IUPAC RECO MMENDAT IONS 2005, Issued by the Division of Chemical, Nomenclature and Structure Representation in collaboration with the Division of Inorganic Chemistry, http://old.iupac.org/publications/books/rbook/ Red_Book 2005. pdf Prepared for publication by Neil G. Connelly University of Bristol, UK Richard M. Hartshorn University of Canterbury, New Zealand, Ture Damhus Novozymes A/S, Denmark, Alan T. Hutton University of Cape Town, South Africa -Inc, 10 March 1992;

[29] bb Darrigol Olivier, Poincare's Light, CNRS: Laboratoire SФhere', UMR 319 Universit'e Paris 7 b`atiment Condorcet, case 7093 5, rue, Thomas Mann 75205 Paris cedex 13, France, http://www.bourbaphy.fr/darrigolpoin.pdf;

[30] Minderle Thomas, A Brief Introduction to Scalar Physics Version 0.2 May 23, 2014, website: scalarphysics.com, http://scalarphysics.com/resources/thomas_minderle/thomas_minderle- a_brief_introduction_to_scalar_physics.pdf

[31] Zohuri Bahman, Scalar Waves, https://www.researchgate.net/publication/327447483;

[32] Zohuri Bahman, All About Wave Equations, https://www.researchgate.net/publication/327447629;

[33] Zohuri Bahman, Scalar Wave Driven Energy Applications, https://www.springer.com/gp/book/9783319910222;

[34] Zohuri Bahman, Principle of Scalar Electrodynamics Phenomena Proof and Theoretical Research, University of New Mexico, Electrical and Computer Engineering Department, Albuquerque, New Mexico USA, https://www.slideshare.net/RobertWeinheimer/principle-of-scalarelectrodynamics-phenomena-dr-bahman-zohuri;

[35] Dollard Eric, "True" Electromagnetism of Nikola Tesla, KazumotoIguchi Research Laboratory October 4, 2017, http://www.stannet.ne.jp/kazumoto/dollardEm-v3.pdf

[36] Dollard Eric, Symbolic Representation of the Generalized Electric Wave,http://gestaltreality.com/downloads/Symbolic\%20Representation $\% 20$ of $\% 20$ the $\% 20$ Generalized $\% 20$ Electric $\% 20$ Wave $\% 20$ by $\% 20$ Eric $\% 2$ 0Dollard.pdf;

[37] Van Vlaenderen, Koen, A GENERALISATION OF CLASSICAL ELECTRODYNAMICS FOR THE PREDICTION OF SCALAR FIELD EFFECTS , Institute for Basic Research P. O. Box 1577, Palm Harbor, FL 34682, USA http://www.swissenschaft.ch/tesla/content/T_Library/L_Theory/EM\%20 Field\%20Research/Vlaenderen\%20SCALAR\%20FIELD\%20EFFECTS. pdf;

[38] Van Vlaenderen, Koen, Electrodynamics on the Möbius Strip General Classical Electrodynamics, Institute for Basic Research, P.O. Box 1577, Palm Harbor, FL 34684 U.S.A., http://www.hrpub.org/journals/article info.php?aid=5192;

[39] Moore Alexander and Healey Timothy, Computation of elastic equilibria of complete Möbius bands and their stability Mathematics and Mechanics of Solids 2019, Vol. 24(4) 939-967 (C) The Author(s) 2018 Article reuse guidelines: sagepub.com/journals-permissions DOI: $\quad 10.1177 / 1081286518761789$ journals.sagepub.com $/$ home $/ \mathrm{mms}$, Alexander Moore Field of Theoretical and Applied Mechanics, Cornell University, Ithaca, NY Timothy Healey Department of Mathematics, Cornell University, Ithaca, NY;

[40] Svozil, Karl and Gernot Pauschenwein, Electrodynamics on the Möbius Strip, Ausgeführt am Institut für Theoretische Physik der Technischen Universität Wien unter der Anleitung von Ao. Univ. Prof. Dr. Karl Svozil durch Gernot Pauschenwein Ing. J. Raab-Gasse 10, 7203 WIESEN 25. 08. 2004 Gernot Pauschenwein e.h., https://arxiv.org/ftp/physics/papers/0411/0411137.pdf;

[41] Sutter P.M. and Tsunefumi Tanaka $\dagger$, Vacuum Energy Density for Massless Scalar Fields in Flat Homogeneous Spacetime Manifolds with Nontrivial Topology, Physics Department, California Polytechnic State University, San Luis Obispo, CA 93407, https://arxiv.org/pdf/grqc/0610051.pdf;

[42] Schmitz Wouter, Particles, Fields and Forces A Conceptual Guide to Quantum Field Theory and the Standard Model, https://ru.b-ok2.org/book/5061884/6ab56b, https://ru.b-ok2.org/book/5061884/6ab56bhttps://ru.bok2.org/book/5061884/6ab56b;

[43] Bearden T.E., Association of Distinguished American Scientists, Utilizing Scalar Electromagnetics To Tap Vacuum Energy, 2311 Big Cove Road, Huntsville, Alabama 35801, http://www.cheniere.org/techpapers/sweet\%20bearden\%201991/sweet\% 20bearden\%201991.htm;

[44] Zahra Haghani 1, * Tiberiu Harko 2, $\dagger$ Hamid Reza Sepangi 3, $\ddagger$ and Shahab Shahidi4, The Scalar Einstein-aether theory, 1School of Physics, Damghan, University, Damghan, 41167-36716, Iran, 2 Department of Mathematics, University College London, Gower Street, London WC1E 6BT, United Kingdom and 3Department of Physics, Shahid Beheshti University, G. C., Evin, Tehran 19839, Iran, (Dated: October 8, 2014), https://www.academia.edu/13354695/Scalar_Einstein-Aether_theory;

[45] Rein, Glen, Effect of the Non Hertzian scalar waves in the immune system, Stanford University Medical Center, Stanford, CA., ELF 
Cocoon International $\quad * \quad$ St. $\quad$ Francisville, IL., https://www.eesystem.com/wp-content/uploads/2018/03/Glen-ReinEffect-of-Non-Hertzian-Scalar-Waves.pdf;

[46] Podgainy, D.V., Zaimidoroga, O.A., Nonrelativistic theory of electroscalar field and Maxwell electrodynamics, Joint Institute for Nuclear Research, 141980, Dubna, Russia;

[47] Attempts to detect the torsion field nature of scalar wave generated by dual Tesla coil system, https://vixra.org/pdf/1607.0130v1.pdf;

[48] Zamsha Vitaly and Shevtsov Vladimir, Magnetic Scalar Field Generator https://vixra.org/pdf/1804.0308v1.pdf;

[49] Grisolía Santiago, Scalar Waves, BioLab C, 2, local 131-PCM,28760 Tres Cantos (Madrid), Spain http://www.bioscalar.eu/en/scalarwaves.html;

[50] Oschman, James, Commentary on the Chapter "Scalar Waves" in "Energy Medicine-The Scientific Basis", Author James L. Oschman PhD, CHURCHILL LIVINGSTONE, EDINBURGH LONDON NEWYORK PHILADELPHIA ST LOUIS SYDNEY TORONTO 2000, by Gerhard W. Bruhn, Dep. of Mathematics, Darmstadt University of Technology, https://www2.mathematik.tudarmstadt.de/ bruhn/Commentary-Oschman.htm;

[51] Scalar Wave Science Fair Project, https://sciencefair.bioenergeticspectrum.com/scalarwavesciencefairprojec t.htm;

[52] Phase transition in ferroelectric domain walls of BaTiO3, Institute of Physics of the Czech Academy of Sciences, https://www.fzu.cz/en/oddeleni/department-of-dielectrics/selectedresults/phase-transition-in-ferroelectric-domain-walls-o;

[53] Minamiosawa, Hachioji, Honcho, Kawaguchi, Saitama Toyonaka, Shimo-Ogino, Atsugi, Theory of Domain Wall Dynamics under Current Gen Tatara1,2, Hiroshi Kohno3 and Junya Shibata4 1Graduate School of Science and Engineering, Tokyo Metropolitan University, Tokyo 1920397 2, PRESTO, JST, 4-1-8 ,332-0012 3 Graduate School of Engineering Science, Osaka University, Osaka 560-8531 4 Kanagawa

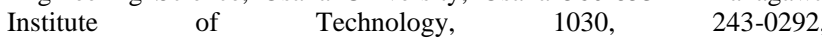
https://arxiv.org/pdf/0801.3517.pdf;

[54] Daniel Fritsch $\ddagger$ and James F. Annett H. H. Wills, Triplet superconductivity and proximity effect induced by Bloch and N'eel domain walls, Physics Laboratory, School of Physics, University of Bristol, Bristol BS8 1TL, UK ,https://arxiv.org/pdf/1507.03977.pdf;

[55] Linsteadt, Stephen, The Heart of Health - the Principles of Physical Health and Vitality, https://scalarheartconnection.com/articles/scalarwaves-and-the-human-mobius-coil-system-1018/;

[56] Meyl, Konstantin - Scalar Waves (First Tesla Physics Textbook), 1st Edition 1996, ISBN 3-9802 542-4-0, http://avalonlibrary.net/Nikola_Tesla/Books/Meyl\%20\%20Scalar\%20Waves\%20(First\%20Tesla\%20Physics\%20Textbook).pdf;

[57] Meyl, Konstantin, Scalar Wave Technology, https://www.yumpu.com/en/document/read/52200792/prof-dr-lngkonstantin-meyl-scalar-wave-technology-;

[58] Meyl, Konstantin, Scalar waves Theory and Experiments, https://www.kmeyl.de/go/Primaerliteratur/Scalar-Waves.pdf:

[59] Meyl, Konstantin, Scalar Wave Technology-Experimental kit for electrical scalar wave, 2003, https://my.ilstu.edu/ 1miones/Summer\%20Research\%20Academy/Scalar \%20Wave\%20Technology\%20-\%20Experimental-

Kit\%20for\%20Electrical\%20Scalar\%20Waves\%20\%5BMeyl\%3B\%202 003\%5D.pdf;

[60] Marjanovic, Goran, Tesla waves ,Belgrade, November 28, 2003. http://www.teslascalar.com/Engl/Tesla waves.pdf;

[61] Marjanovic, Goran , Tesla waves, Belgrade, November 28, 2003. http://www.teslascalar.com/Engl/Tesla_waves.pdf;

[62] NASA/CR-2005-213749, Advanced Energetics for Aeronautical Applications: Volume II, David S. Alexander MSE Technology Applications, Inc., Butte, Montana, April 2005 http://www.rohnermachine.com/Files/NASAAdvanced Energetics.pdf. 